\title{
Place of the Freedom of Information Act in Promoting Agricultural Extension under the Agricultural Transformation Agenda in Nigeria
}

\author{
*Ismail, F.O., Tenuche S.S. and A.A. Wahab \\ National Agricultural Extension and Research Liaison Services, Ahmadu Bello University, \\ Zaria. \\ *Correspondence: E-mail: prgamatich@gmail.com , pragmah@yahoo.com Tel: \\ 08099443554
}

\begin{abstract}
This paper takes a critical look at government's efforts to make information available to all Nigerians through ICT the Freedom of Information Act of 2011 with a view of leveraging them for effective and efficient electronic extension service delivery as a component of the Agricultural Transformation Agenda (ATA).
\end{abstract}

Keywords: Transformation, Freedom, Information, Act, Rural, Development and Technology.

\section{Introduction}

Technology, such as Information and Communication Technology (ICT) is a persuasive force for economic, social, political and educational reforms. The food requirements and economy of any country, poor or rich, developed or developing, depends substantially on the level and quality of the technology and research available to its agricultural workforce. Agricultural reform is occurring throughout the world and one of its tenets is the introduction and integration of ICT in the sector. The successful integration of any technology, thus ICT, into agriculture warrants careful planning and depends largely on how well policy makers understand and appreciate the dynamics of such integration. As a result, nations worldwide have recognized the developmental opportunities and the challenges of the emerging information age characterized by Information and Communication Technologies (Ghana ICT4AD, 2003).

Globally, these technologies are propelling national development efforts and many countries are exploring ways of facilitating their development process by developing, deploying and the exploiting them. Nigeria is not left out in this scramble. Since 2003, when the GSM telephone services properly penetrated the nation's market, governments at different levels have keyed into various developmental programmes involving the utilization of modern telecommunication system.

As of December 2011, an estimated 45 million Nigerians had used the Internet at least once- compared with 200,000 in the year 2000 (www.oafrica.com).

\section{ICT, Extension and Agricultural Transformation}

Information Communication Technologies (ICTs) simply refer to electronically controlled channel of information. The technologies (hard and soft) include radio, television, Geographical Positioning System (GPS), Internet, telephones, laptops, cameras for the former (hard) and numerous programmes for the latter. For many years they have shaped and continue to reshape the existence of mankind in information gathering, processing and 
disseminating. Human advancements in communication have been made possible by these technologies.

The World Summit on the Information Society (WSIS); a pair of United Nations-sponsored conferences about information, communication that took place in 2003 in Geneva and in 2005 in Tunis, had as one of their chief aims the bridging of the so-called 'Global Divide' separating rich countries from poor countries by spreading access to the Internet in the developing world (www.Wikipedia.com). The conferences have so far established a World Information Society (WIS).

The integration of ICT into our daily lives has changed the modern society in many ways which is known as digital revolution, and therefore new opportunities and threats had been raised (www.Wikipedia.com). While governments around the world are hopeful to solve many problems using ICT, they are silently concerned with digital divide at international level and as well as at national front which could lead to new classes of those who have access to ICT and those who have not. The 'digital divide', a technical situation describing the technology gaps between developed and underdeveloped or developing countries requires global attention if the United Nations (UN) Millennium Development Goals(MDGs) must be globally attained. And so, on December $21^{\text {st }} 2001$, a UN General Assembly resolution (Resolution 56/183) endorsed the holding of the World Summit on the Information Society (WSIS) to discuss on information society opportunities and challenges on how to implement ICT to facilitate achieving Millennium Development Goals.

One Hundred and seventy- five (175) countries took part in the first phase in Geneva in 2003 where they adopted a Declaration of Principles as a road map for achieving an information society accessible to all and based on shared knowledge with a Plan of Action with a goal of bringing 50 percent of the world's population online by 2015 . But the meeting did not spell out specifically how this might be achieved or how the Internet would be governed and funded. However, the Civil Society delegates from NGOs produced a document called "Shaping Information Societies for Human Needs" that brought together a wide range of issues under a human rights and communication rights - (legal), though the WSIS Action Lines itemized: a). The role of public governance authorities and all stakeholders in the promotion of ICTs for development; b). Information and communication infrastructure; c). Access to information and knowledge; d). Capacity building; e).Building confidence and security in the use of ICTs; f). Enabling environment and ICT Applications for - E-government, E-business, E-learning, E-health, E-environment and E-agriculture and others use of ICT for E-science, Media, and Ethical dimensions of the Information Society and International and regional cooperation.

If e-agriculture is possible, then agricultural 'extension' a general name for the application of scientific research and new knowledge to agricultural practices through farmers' education must incorporate ICT (www.Wikipedia.com). However, there is no widely accepted definition of agricultural extension. The ten examples given below are taken from a number of extension publications over a period of more than 5 decades to show how extension itself has evolved with the dictates of time: I. 1949: The central task of extension is to help rural families help themselves by applying science, whether physical or social, to the daily routines of farming, homemaking, and family and community living. II. 1966: Extension personnel have the task of bringing scientific knowledge to farm families in the farms and homes. The object of the task is to improve the efficiency of agriculture. III. 1973: Extension is a service or system which assists farm people, through educational procedures, in improving farming methods and techniques, increasing production efficiency and income, bettering their levels of living and lifting social and educational standards. IV. 1974: Extension involves the conscious use of communication of information to help people form 
sound opinions and make good decisions. V. 1982: Agricultural extension: Assistance to farmers to help them identify and analyze their production problems and become aware of the opportunities for improvement. VI. 1999: The essence of agricultural extension is to facilitate interplay and nurture synergies within a total information system involving agricultural research, agricultural education and a vast complex of information-providing businesses. VII. 2004: Extension [is] a series of embedded communicative interventions that are meant, among others, to develop and/or induce innovations which supposedly help to resolve (usually multi-actor) problematic situations.

The modern field of extension now encompasses a wider range of communication and learning activities organized for rural people by professionals from different disciplines, including agriculture, agricultural marketing, health, law and business studies. Communication in extension involves two things: How and Why? These two questions are expanded further in extension to often describe a model of communication involving the transmission of messages from senders" to "receivers". In this model, it is clear that the senders are in control of the communication process. Today, strategic communication theorists like Cardoso, Melkote and Frank are advocating a shift from such sender dominant paradigms of communication with which paternalistic communication process is entrenched. Melkote and Leslie (2001), offers a refreshingly different perspective from standard Western recitation of material on the topic of communication for development. As a matter of the dynamics of communication, the author has improved on the first edition which was published in 1991 in the 2001 edition when he listed more options for communication for development in the Third World to include environment, human rights, feminism, nutritional requirements, religion etc. The aspect of human rights extends to the right to know and have access to public information which is foreclosed by the Freedom of Information Law.

With the influence of theorists like Melkote advocating for relative setting design and implementation of development projects, in many countries, especially in the technologically disadvantaged ones, paternalistic extension is gradually being replaced by more participatory approaches, in which the knowledge and opinions of farmers are considered as important as that of researchers or government officials. Participatory approaches involve information-sharing and joint decision-making. The terms "interactive" and "bottom-up" have been used to describe these approaches. At present, no single description has replaced the transmission model that is referred to above, but two ideas are becoming widely accepted: Communication in the context of participatory extension cannot be described in a linear manner with distinct groups of senders and receivers; instead, extension activities take place within a knowledge system consisting of many actors who play different roles at different times. What takes place in communication as a negotiation process is a dialogue, with actors collaborating in the construction of shared meanings rather than simply exchanging information- a characteristic for requiring and obtaining 'government information' by invoking the Freedom of Information Act by the public. These related but separate fields of agricultural communication have emerged to contribute to in-depth examinations of the communication processes inclusive of guiding laws among various actors for the transformation of the agricultural system among other things.

Crops that are resistant to extreme weather or plant diseases or that can produce life-saving vaccines, medicines, and vital nutrients; farm machinery guided by Global Positioning System satellites; new farming practices that improve air and water quality and reduce soil erosion; instant market information and available channels for prompt and fair judgments by peasants on communal clashes emanating from struggle for limited farm land and water sources via the Internet requires faster and timely communication (available and affordable) even at the most remote areas of any nation. The International Ministerial Conference and Expo on Agricultural Science and Technology held from June 23 to 25, 2003, in Sacramento, California produced a report to help frame discussions on how 
science and technology can help meet the world goals of increased agricultural productivity, enhanced food security, and stronger economic growth. Ann Veneman, United States of America's Secretary of Department of Agriculture said in that report that developed and developing countries must work in partnership to strengthen global food security and reduce world hunger, and ensure access to the benefits of modern agriculture. Though the report submitted that advances in science and technology contributed to substantial gains in global agricultural productivity in the 20th century, it was not sure all regions benefited equally. Therefore, it remains a challenge in the 21st century to ensure that all countries have access to innovations and discoveries that could raise incomes, reduce hunger, and improve nutrition through viable policy, regulatory, and institutional frameworks to support science and technology.

What Nigeria is doing by reforming the agricultural sector is a compliance to face such challenges. The future of agriculture is not on some distant horizon; it is around us today, with innovations emerging at a breathtaking rate (USDA, 2003). Innovations in biological and information sciences have resulted in several emerging fields that hold promise for the development of future agricultural technologies. Thus, the legal profession must also be challenged to fashion enabling laws for the entrenchment of these prospective fields in clear terms. The new fields of bioremediation, nanotechnology, genomics, and bioinformatics will increase knowledge for sharing to improve sustainable agricultural production and protect ecosystem functions in developed and developing countries alike. In the meantime, the big question will be whether Freedom of Information Laws can be interrogated on such intricate issues by farmers. These advances hold great promises, but the full benefits of scientific breakthroughs will not be realized without the dissemination and adoption of new technologies backed up with functional rules, procedures or laws. Countries with strong research and information technology capacity will offer a supportive environment for technology development and investment in high communication system including software development and production. Like Nigeria, many countries have crucial decisions to make in meeting their sustainable agricultural goals, these decisions need to be made and implemented based on decision makers' knowledge of their countries' unique environmental, social, legal and economic characteristics that must influence the utilization of information technologies beyond the national or international communication barriers. Lack of infrastructure, poor natural resource endowments, and restrictive national and international communication policies can all hinder technology development, transfer, and adaptation. These impediments can also hinder farmers from adopting sustainable agricultural practices.

Barriers to the development and transfer of the newest science, such as intellectual property rights restrictions should be critically examined in the light of any communication policy. Where countries can make agricultural policy choices based on sound science and access to accurate information, the chances of attaining national goals (reformation) are high. Vikash Kumar (2012) capped it all when he said "a policy sharing infrastructure that enables a semantic rule would create one set of environmental, physical and contextual settings to be translated, while maintaining the underlying semantics, for use in a situation when those settings/parameters change through policies on smart home and mobile commerce use."

\section{The Fol Act, Extension and Agricultural Transformation}

According to Wikipedia online, Freedom of Information Laws detail legislation that gives access by the general public to data held by national governments. These laws establish a "right-to-know" legal process by which requests may be made for governmentheld information, to be received freely or at minimal cost. Over 90 countries (Nigeria not inclusive as at December 2012) have implemented fully some form of freedom of information legislation. 
A basic principle behind most freedom of information legislation is that the burden of proof falls on the body asked for information, not the person asking for it. The person making the request does not usually have to give an explanation for his actions, but if the information is not disclosed a 'valid' reason has to be given.

As a result of the chronological evolution of information and communication technologies, the term "ICT" has-in so-called developed countries, at least-largely been used as a reference to the basic elements (e.g. telephone network) of an information and communication system but much less with regard to advanced IC technologies such as the Internet and regulated by laws. In the context of developing countries, where communication systems are often built from scratch, it is easier and more appropriate to conceptualize "ICT" in a broader sense, and to include every information and communication technology available as one single set of opportunity (Moore and Palfrey, 2003). Accordingly, the authors believe that laws on the use of ICT are "ecosystem", and dependent for functioning on a variety of complementary contributions. The foundations of an effective legal system 'are in the procedure of law, in addition to the materials', they argued. Moore and Palfrey (2003) opined that in many developing countries the substance of law is-on paper-well developed. What is missing is the foundation of practice. They provided a chart to introduce the sorts of process deficiencies that may be present in developing countries, and that impinge on the development of digital business ecosystems including the access to government information online. This list of deficiencies, inverted into competencies, provides an idea of the capabilities that need to be assembled at the roots of Nigeria's legal ecosystem. A major challenge, now in the face of the Freedom of Information Act, is how to stimulate of the growth of such capabilities. This, in a way, will help Nigerians see information and communication technology as a social activity just as agriculture was perceived a social activity by Frank Vanclay.

Vanclay (2004) argued that sustainable agriculture which is part of transformation can only be possible if agriculture is understood as a social and cultural activity where farmers understand farm management practices beyond the technical application since farming is a practical manifestation of socio-cultural expressions. Thus, the application of any law should also survive in this arena with the understanding that law works well where the socio-cultural entities are integrated into its crafting and implementation. Freedom of Information Act is an act that makes provision for the disclosure of information held by public authorities or by persons providing services for them (Robert, 2000). The importance of the right to information or the right to know is a constant refrain in the mouths of development practitioners, civil society, academics, the media and governments (Mendel, 2008). This means that the act enables one see a wide range of public information because it gives the right to ask any public body for all the information it possesses on any subject. 'Any public body' in the above refers to any government institution (including agricultural research institutes). The Law also provides for "multi-track" processing of requests based on the amount of work involved (Mendel, 2008). The essential records of information/documents that every citizen has right to access in an organization include: I. Orders made in the adjudication of cases. II. Statements and interpretations of policy of an institution. III. Factual reports, inspection reports and studies prepared by the institution on their behalf. IV. Information related to receipt of expenditure or other funds. V. Documents confirming information on names, salaries, titles and dates of employment of all categories of employees and officers. VI. Documents containing the right of the state, the public and local governments. VII. Files containing applications for any contract, permit, grants or agreements. VIII. List of reports, document, studies or publications prepared by independent Contractors for the institution.

Ironically, extension services are entrenched on FREE dissemination of information about best practices and innovations to farmers. However, where research institutes are in 
collaboration with international counterparts and an innovation is made, can a Nigerian farmer invoke the Act to request for such information from the external body where such request has been denied domestically; with the understanding that part or the whole research activities leading to the discovery was conducted in Nigeria or with public fund? Much has been said about the Freedom of Information Act regarding its functionality to Press Freedom and Free Journalism but little has been done on Intellectual Property Rights and transfer of technology rules. This is where extension service reform must dig deeper.

Sadly, Nigeria has no Agricultural Law per se; the available cooperative society procedures and agric banking rules cannot solve these problems. Access to government information is a human right (UNHRC, 2012). On July 21, 2012, the United Nations Human Rights Committee adopted General Comment 34, detailing its interpretation of governments' obligations to protect freedom of opinion and expression, as guaranteed by Article 19 of the International Covenant on Civil and Political Rights (ICCPR). This rights, (freedom to know) according to Nigerian Minister of Information, Labaran Maku during the National Workshop on the Fol Act in May 2012,"is good but it can be very corrosive...the law must be studied properly to understand how to apply it" (The Nation, 2012). Within the African continent, Nigeria is now the ninth country to have passed Fol bill into law, the others being Angola, Ethiopia, Guinea, Liberia, Niger, South Africa, Uganda and Zimbabwe (www.Wikipedia.com).

However, in the Nigerian context, it has been observed that the Act is in conflict with other laws like the Official Secrets Act, the Evidence Act, the Public Compliant Commission Act and the Statistics Act. The most outstanding laws here are the Evidence Act, the Public Compliant Act and the Statistic Act. These Acts and the Fol Act implicitly hold an agricultural extension agent liable where data, figures and facts are manipulated or 'cooked-up' for public consumption. It is not uncommon to read in the news that some government agencies in the country disseminate wrong and concocted research reports. Though, nobody has been out rightly convicted in this regard, but the existence of such activity has put some dust of doubt on information coming from many research institutions in Nigeria. Again, it is a common thing for some extension workers to intentionally misinform local farmers or collaborators in order to get some projects done quickly without recourse to approved rules or standards. These acts are against the spirit of the Fol Act on transparency, accountability and public interests. 
Table 1: Process deficiencies for bionetwork and legislative body rules of law in developing nations

\begin{tabular}{l} 
Legal Deficiencies \\
\hline Foundation \\
Lack of an established ethos of \\
"rule of law" on Freedom of \\
Information.
\end{tabular}

Corruption of officials

Lack of documentation, lack of access to documents and records. This may pertain to official government decisions, laws and rulings, and results of hearings and other administrative or enforcement processes in terms of disputes on land by farmers.

Legal process issues

An ability to set and shape the law

Absence of relevant laws regarding substantive issues

Lack of effective civil and criminal procedure. "Good laws" but little corresponding process, limited translation into administrative organizations, monitoring, and enforcement.

Lack of effective means of enforcement and relief

\section{Examples}

Limited experience with binding business contracts, no expectation that contracts will be enforced if a conflict arises; the result is that cooperation among members of the digital ecosystem(Nigerians) can be impaired-and that the expertise of the community in using contracts is not developed.

Willingness of the state to abrogate agreement made by previous governments. The result is that investors are reluctant to bring capital to projects that might be helpful to the digital ecosystem.

Government contracts go to local favorites, creating unfair competition for competent members of the ecosystem (farmers), and often causing essential functions not to be performed effectively.

It is often very difficult to know what action has been taken by government, even in official actions of cabinet or the President. Laws are not available on-line, nor are court cases. Records of hearings are often not kept, or are not available

In some cases constitutions as well as specific laws have been determined by colonial tradition, dictatorships, or the intervention or requirements of international organizations. In cases the legislative system or the judiciary does not function effectively.

In some cases, there is no relevant law. Example in Nigeria there is no laws which make it difficult to create certain classes of agricultural related interests to protect farmer rights.

In other case, laws exist but are not made operational. The laws are in some cases adopted but not acted upon. For example, an independent regulator may be mandated in statute, but not organized and staffed.

Even when a judgment(on denial of access to information) can be obtained, it can be very difficult to enforce it or to gain relief either in the 
Conflicting processes with no clear path to appeal or reconciliation

Policy-based overrides to the legal system

Official policies and practices that distort the market form of monetary compensation, in the form of rectifying a past harm, or in the form of changing the behavior of the parties to agricultural development issues.

For example, a court may provide one remedy, and an administrative body another-but with no way of reconciling the decisions in cases of conflict between the outcomes on failed agricultural development projects.

In all countries the working of the market may be distorted to achieve social ends. In doing so, states also sometimes make laws to support such policies, and overturn existing statues and conditions, in a manner that undermines the consistency of law that enables rational business investment. For example, employment action and corporate social responsibility system in Nigeria that implore that substantial portions of businesses be set aside specially for company and government agencies host community.

The result can be the undermining of the market, and slowing the rate of growth and diversity in the digital business ecosystem from which farmers may need constant information especially for the utilization of the Value Chain Competitive system in Nigeria.

Adapted from: Moore and Palfrey. (2005). 'ICT and Entrepreneurship: Digital Business Ecosystems and the Law' at http://cyber.law.harvard.edu/bold/devel03/modules/episodell.html

\section{Conclusion}

Most of the time, in many countries, the public cannot flow with government complicated policies or rules. Individuals and corporate bodies are pre-occupied with personal interests that will not allow them capture comprehensively whatever government has for then in any information package. Nigerian farmers are not exclusive. Public issues, especially the ones on transformation or change require some trade-offs that are difficult to capture by sound bites and concocted figures. Immersing the public in the details of competing policy options can yield better results. The free flow of information and ideas lies at the heart of the notion of development and is crucial to effective respect for human rights. In the absence of respect for the right to freedom of expression, which includes the right to seek, receive and impart information and ideas, it is not possible to exercise the 'right to farm; human rights abuses take place in secret, and it is not easy to expose corrupt, inefficient extension agent with falsified figures where access to real information is limited or not available at on the Internet. Central to the guarantee of a free flow of information and ideas is the principle that public bodies hold information not for themselves but on behalf of the public, extension agents and research institutes must therefore give to the public accurate and undiluted information for the sake of public transformation. 
A number of paradigmatic changes sweeping the globe have undoubtedly contributed to growing acceptance of the right to information. These include the transitions to democracy, climate change, food security, epidemics and terrorism. They also undoubtedly include massive progress in information technology which has changed the way societies relate to and use information, and which has, broadly, made the right to information more important to all citizens. Among other things, information communication technology has generally enhanced the ability of ordinary members of the public to control public opinion, to hold leaders to account and to feed into decision-making processes. This, in parallel, has led to greater demands for the right to information to be respected even by research and extension agents. There are a number of utilitarian goals underlying widespread recognition of the right to information in agriculture, information is the "water in agriculture". Information is an essential underpinning of modern farming at every level. In general, agriculture today is about the ability of individuals to participate effectively in decision-making that affects them all round the season. Effective participation at all levels depends, in fairly obvious ways, on access to information, including information held by public bodies.

Agricultural transformation is not simply a political scenario change. For agriculture transformation initiatives to fulfill their proper function, farmers must have access to real time information. It is difficult, for example, to provide useful input to a policy process without access to the thinking on policy directions, for example in the form of a draft policy, as well as the background information upon which that thinking is based. Information Communication Technology (ICT) enhances participation which is central to sound extension and decision-making that can trigger a virtuous cycle of development. According to Stiglitz (2002), unequal access to information allows officials "to pursue policies that are more in their interests than in the interests of the citizens". Improvements in information technology and participatory transformation programme can reduce the scope for these abuses. Meanwhile, there is an aspect of the right to information that is often neglected - the right to facilitate effective business practices with this information by commercial farmers. The right to information is most commonly associated with the right to request and receive information from public bodies. But this is not the only thing, one further aspect of this right is slowly starting to emerge; unlike the other two aspects of the right, which relates to information already held by public bodies; this third aspect posits a positive obligation on States to ensure that certain key categories of information are available. The 'right to truth' has also been recognized by international courts in the human rights context, and also in the context of environmental threats with preference for agriculture.

Extension services and agricultural transformation programme in Nigeria must aggressively be concerned about all these so as to utilize the potentials of the ICTs. The greater utilization of the Fol Act can lead to the birth of a comprehensive national agricultural law to cater for the rights of Nigerian farmers as innovations continue to push the status of agriculture from subsistence to commercial, especially in the line of value chain extension system. Anything short of this, the law (Fol Act) will subsist as another instrument of hegemony for the suppression of right to information in the agricultural sector. 


\section{References}

'ICTs for agriculture in Africa' at http://siteresources.worldbank.org/...Agriculture.pdf, Retrieved: 13-04-2013.

Ismail, F O. and Tenuche, S.S. (2012). 'The media and information communication technology: Inevitable tactics for sustainable rural development in Nigeria', A paper presented at the 2012 Annual International Conference of the Nigeria Rural Sociological Association, University of Ibadan, Nigeria.

Melkote, S. and Leslie Steeves, H. (2001). Communication for Development in the Third World: Theory and Practice, London, Sage.

Mendel, T. (2008). 'Freedom of Information: A Comparative Legal Survey' at www.fas.org/sgp/foia/comparative.pdf, Retrieved: 18-04-2013.

Moore, J. and Palfrey, J. (2003), 'ICT and Entrepreneurship: Digital Business Ecosystems and the Law' at http://cyber.law.harvard.edu/bold/devel03/modules/episodell.html, Retrieved: 19-04-2013.

Robert, A. (2000). Freedom of Information Act: Parliament of the United Kingdom at http://www.ukfreedom.com. Retrieved: 26 -04 2013.

Stiglitz, J. (2002). Transparency in government in World Bank Institute, The Right To Tell: The Role of the Mass Media in Economic Development, (Washington, D.C.), p. 28.

Stiglitz, J. (2002). Participation and Development: Perspectives from the Comprehensive Development Paradigm. Review of Development Economics, 6 (2):163-82.

The Ghana ICT for Accelerated Development (ICT4AD) Policy at http://www.nca.org.gh/...oads/Ghana ICT4AD Policy.pdf, Retrieved: 16-04-2013.

The Universal Declaration of Human Rights (1948), UN General Assembly Resolution 217 A (III), 10December 1948, Article 21.

Truth and Access To Information About Past Human Rights Violations. 'Who Wants to Forget?'

(London: ARTICLE 19, 2000), p. 5. at www.article19.org/docimages/869.htm.

United Nations Human Rights Commission at http://www.ohchr.org, Retrieved: 22-04-2013.

United States Department of Agriculture at http://www.usda.gov.

Vanclay, F. (2004). Social principles for agricultural extension to assist in the promotion of natural resource management. Australian Journal of Experimental Agriculture at www.publish.csiro.au/journals/ajea, Retrieved: 06-03-2013.

Vikarsh, K. (2012). A Semantic policy sharing infrastructure for pervasive communities in the semantic web: Research and applications. Lecture Notes in Computer Science Volume 7295, 2012, pp 859-863 at http://link.springer.com/chapter/10.1007/978-3-64230284-8 71., Retrieved: 19-04-2013. 